\title{
Marriage, Norm Orientation and Leaving the Parental Home: Turkish Immigrant and Native Families in Germany
}

\author{
Michael Windzio, Can Aybek
}

\begin{abstract}
This article investigates differences between native Germans and Turkish immigrants in the timing of leaving their parental homes in Germany. By using event history models, it is shown that leaving the parental home is closely linked to the intervening life-event of marriage, particularly among Turkish women. Moreover, there are interaction effects of religious norm orientation with gender which differ between native Germans and Turkish immigrants. In contrast to Turkish immigrants, the linkage of marriage and leaving home became much weaker over birth-cohorts with time in the group of German women. Finally, analyses of sequence patterns also show remarkable differences between native Germans and Turkish immigrants in the process of leaving home. Religious norm orientation turns out to be less important in the Turkish group than in the native German group.
\end{abstract}

Keywords: Leaving the parental home - Living arrangement · Transition • Adulthood · Germany · Native German · Immigrant Turkish · Co-occuring event $\cdot$ Marriage $\cdot$ Religion $\cdot$ Norms

\section{Introduction}

In modern western countries, leaving the parental home has become one of the major markers of the transition into adulthood (Corijn/Klijzing 2001). Today, many adolescents leave their family in order to pursue either higher education or occupational training. Marriage and childbirth, which actually are the more fundamental transitions in life, are postponed in favour of training or higher education and the entry into the labour market. At the same time, western countries have become more diverse in cultural and religious terms. In some countries, such as Germany, the third and fourth generations of immigrants' descendants are growing up. It remains to be seen, however, which type of a trajectory into adulthood young people of migratory background follow, and, for instance, if they show a pattern of leaving home similar to that of the native group in the respective country. 
The largest group of immigrants in Germany stems from Turkey, and there are empirical findings highlighting differences in many realms of life between native Germans and Turkish immigrants, such as labour market outcomes (Kalter/Granato 2004) or marriage patterns (Gonzalez-Ferrer 2006; Kalter/Schroedter 2010). Since family structures and intergenerational relations differ between Germany and Turkey (Nauck 1989; Kağıtçıbaşı/Sunar 1997), we expect that the patterns of leaving the parental home differ between these two groups as well. The role of the family in terms of the autonomy and dependence of individual family members in the Turkish context is clearly different from patterns found in northern European societies (Liljeström/Özdalga 2002). For instance, in Turkish society, pre-marital residential autonomy (Goldscheider/Goldscheider 1993) is found to be much less common (Koç 2007). Analyses conducted on immigrant and native-born youth in the Netherlands led to similar observations that young men and particularly women of Turkish descent are more likely to follow a traditional path that leads them from the parental home directly into marital cohabitation (Zorlu/Mulder 2011; Windzio 2011).

Departing from findings presented in literature on the topic, we expect that the event of leaving the parental home is more closely related to marriage in the Turkish group than in the native German group. In contrast to Windzio (2011), we distinguish between the pre- and post-marriage period and also devote particular attention to gender differences in religious norm orientation. With regard to changes over time, however, it is not clear whether the degree to which leaving home and getting married coincide has changed in the same way in both groups: in the context of the fundamental value changes taking place in many western European countries since the late 1960s, we indeed expect that the synchronicity of marriage and leaving the parental home has substantially declined in post-war Germany as a result of trends in modernisation, secularisation and individualisation (Konietzka/Huinink 2003; Konietzka 2010). The question of whether such a decline also occurred in the group of Turkish immigrants will be tested empirically by using data from the German Gender \& Generations Survey Programme.

We further ask whether the expected difference in home-leaving patterns can be explained by the degree of religious norm orientation, which we measure through indicators concerning the importance of religious ceremonies and activities. One argument for considering religious norm orientation in this context is that the process of family formation has always been awarded special attention in religious norms and by religious authorities, because the family is an important medium for spreading and reproducing religious systems (Zinnecker 1998). Moreover, religion constitutes a basic element of culture in classical sociology (Weber 1978). Today, there are many empirical results showing the renewed importance of religion and religious diversity in western countries, especially in settings where the host society is predominantly Christian and a large share of immigrants are Muslim (Modood et al. 2006).

It will be argued that the timing of moving out of the parental home should differ between natives and Turkish immigrants in Germany, particularly with respect to gender (cf. Esmer 2008). A comparison of survivor functions will provide first insights into differences in the timing of moving out of the parental home. It will then 
be investigated to what extent the intervening life-event of marriage has an impact on the rate at which the parental home is left and whether there are interaction effects of religious norm orientation with gender. Finally, by using a simple analysis of sequence patterns, how religious norm orientation influences the order of the events of marriage, moving out and childbirth will be examined for women in both groups.

\section{Theory and research}

It is still an open question when and under which conditions, next to education- or work-related circumstances that might trigger the spatial mobility of adolescents, norms affect individual decisions on the timing and mode of leaving the parental home. With regard to age norms, i.e. the influence of informal social norms in a specific society concerning the "best" age at which young people should move out of the parental household, there is plenty of evidence in the literature (e.g. Billari/Liefbroer 2007; Settersten 1998). We argue that this process is also strongly related to other types of norms, such as religious and family norms. The groundbreaking study by Goldscheider and Goldscheider (1993) illustrates that religious norms in culturally diverse societies, such as the USA, influence patterns of leaving the parental home. As is commonly known, religions are normative systems which relate the everyday conduct of life to the satisfaction of spiritual needs, for example through the promise of salvation under the condition of appropriate behaviour (Weber 1999). In this regard, religion also influences attitudes towards intergenerational relations and marriage. This is of special importance, taking into consideration that marriage behaviour is closely linked to the reproduction and maintenance of religious systems (Windzio/Wingens 2014). However, religious claims regulating marriage behavior are often in competition with other functional requirements of society, such as regulating kinship, social ties and inheritance (cf. Schweitzer 2000; Segalen 1986). For this reason, we argue that the behavior of leaving home might be even more influenced by norms related to attitudes towards the family and kinship system and is not necessarily motivated by religious considerations alone (cf. Kağıtçıbaşı/Sunar 1997; Nauck 1989; White et al. 2015). In order to understand the particular mechanisms behind patterns of leaving the parental home, it is important to differentiate between the influence of religiousness as such and the impact of familial norms.

The concept of normative bonding describes ties of support and reciprocity within communities and families. Social integration by normative bonding can be in sharp contrast to the self-interested individual rationality when an individual need - such as education - is subordinated to the fulfilment of normative expectations of the community (Halpern 2006: 20). Similar to Portes' (1998) concept of negative social capital, normative bonding can be an obstacle to individual freedom. In conjunction with monitoring and social control in normatively bounded communities, this is what turns the process of leaving the context of the natal family into an event of high social significance. Leaving the parental home, from the perspective of the 
parents, for instance, could be interpreted as an event that leads to a loss of control over the child. Partnership and marriage are not considered to be a merely individual matter, but also a familial issue that serves the end of establishing an orderly life in accordance with normative expectations of the parental generation and the co-ethnic community. Studies on family structures in Turkish society underscore the high level of interdependence and interaction between married couples and their families of origin (Hortaçsu 2003, 2007). The parents of both sides contribute considerably to the financial burden of marriage and the establishment of a new household. Furthermore, the natal family continues often to provide goods and services, such as childcare, that might be important to young couples (Hortaçsu 2003; Kalaycıoğlu/Rittersberger-Tılıç 2000). For immigrant families of Turkish descent in Germany, Steinbach (2013: 1114) observes that the frequency of parent-adult child contact is significantly higher than in native German families. From this perspective leaving the parental home gains a different meaning that is strongly embedded in a familial context.

Studies using the World Values Survey still reveal notable differences in average value orientation between citizens of EU member states and Turkey (Esmer 2008; Gerhards 2004). It has also been shown that family-related norm orientation regarding the "economic value" of children differ greatly between Germany, Turkey and Turkish immigrants (Nauck 1989: 261), although at least to some degree differences in the normative structure of intergenerational relationships can be explained by educational differences (1989: 261). Strikingly, in Nauck's (1989) analysis, differences in normative orientation and behavioural practices between respondents in Turkey and Turkish immigrants in Germany were rather modest. In a similar manner, Kağıtçıbaşı and Sunar (1997) argue that, despite trends towards modernisation, family relations in Turkey are still to a high degree characterised by a "culture of relatedness".

While research commonly hints at cultural differences between immigrants and natives (Gerhards 2004; Nauck 1989), there are nonetheless only a few studies linking patterns of leaving the parental home to norms and culture (Billari/Liefbroer 2007; Huschek et al. 2010; Zorlu/Mulder 2011). Diehl et al. (2009) found a correspondence of higher levels of religious adherence with less egalitarian gender roles in the group of Turkish immigrants in Germany, but not in the group of native Germans. Moreover, Dieh/ and Koenig (2009: 311) highlighted that levels of religious adherence did not decline for Turkish immigrants in the second generation, but in certain aspects in fact increased. When persons with more traditional values and higher levels of religious norm orientation have stronger ties to their family, moving out of their parental home early on in order to achieve pre-marital residential autonomy should be less likely. Consequently, high levels of religious norm orientation might slow down the process of leaving the parental home. Moreover, due to far-reaching cultural changes in western societies since the late 1960s, one might expect a linear trend in individualisation and "de-linking" of life-events across birth cohorts in the native German sample. Nonetheless, it remains to be seen whether Turkish immigrants in Germany show a similar trend. 


\section{Data and Methods}

The empirical analyses are based on the first wave of the German Generations and Gender Survey where among other things retrospective data on life events was collected. The data set consists of two independent random sub-samples which include $\mathrm{N}=10017$ German-speaking persons and $\mathrm{N}=4045$ Turkish citizens who live in Germany as first and second generation immigrants (Ette et al. 2007: 17; Ruckdeschel et al. 2006: 13). Since the sample of German-speaking persons also includes Turkish immigrants, this group's results have been shifted to the Turkish sample. All other immigrant groups were excluded from the German-speaking sample, so that $1^{\text {st }}$ and $2^{\text {nd }}$ generation Turkish immigrants can be compared with native Germans. Turkish respondents who moved out of the parental home while still in Turkey were excluded from the sample. The timing of important life-events, such as leaving the parental home, was measured on a monthly basis, so continuous-time event history analysis and the method of episode splitting (Blossfeld et al. 2007: 141) could be applied. With regard to the event of interest, which is the timing of leaving the parental home, the risk exposure starts at the age of 14 . Age 14 is fairly close to the legal marriage age of 16 . However, we found several marriage-related cases of moving out at slightly earlier ages than 16 and hence decided to start the risk period at age 14 in order to include these events in our sample. This slight extension of the risk period does not influence the overall risk ratios.

Persons who do not hold any school diplomas as well as persons with low levels of secondary education are defined as having a low level of education. Secondary education diplomas qualifying for university admission ("Abitur" or "Fachhochschulreife") were defined as a high level of education, intermediate level diplomas of secondary education ("Realschule", "mittlere Reife") or similar diplomas as a medium level of education.

The data provides information on the father's and the mother's occupation and education when the respondent was 15 years old. The following categories are used for the occupational status of the parents: 1. no employment, 2. blue-collar workers, 3. farmers and self-employed, 4. white-collar workers, civil servants, professionals (reference group). The educational certificates obtained by the parents are categorised as high education (master craftsmen, Abitur, academic) and other education.

Unfortunately, with respect to the timing of general and occupational education, we can only discern the time the general education ended and the time when the highest occupational certificate was obtained - which might not necessarily coincide with the end of an individual's general education. Therefore, the period during which persons move out of the parental home due to entry into occupational training or higher education has been defined to start two months before completing general secondary education and to end 38 months later (training/higher education, end school $-2 /+36$ month).

With regard to intervening events in life, the exact co-occurrence of such events is rather unlikely. We assume that these events do not happen at precisely the same point in time (here: within the same month), but in temporal proximity to each other during a pre-defined time period. Therefore, we used an interval long enough to 
cover time for activities which are usually related to marriage, such as the organisation of a wedding, before and after moving out. Twelve-month intervals were used with the dates of marriage and the birth of the $1^{\text {st }}$ child as midpoints (marriage period (+/- 6 Mon.), birth of 1 st child period (+/- 6 Mon.)). In Table 1 we estimate the effects of two dummies and regard the marriage period as a reference category: the first dummy (" $6+$ months before marriage") indicates the period of potential pre-marital residential autonomy (pre-marriage period), the second dummy (" $6+$ months after marriage") indicates the period of 6 months and more after marriage.

Regarding marriage, it should be noted that in the group of Turkish immigrants, more than 90 percent of all marriages are intra-ethnic, that is, Turkish immigrants choose partners mainly from the Turkish community (Kalter/Schroedter 2010: 2021), which is higher than suggested by the demographic opportunity structure (resulting from the size of the group). In contrast, in the native German group, interethnic marriages have a similar share, but the opportunity structure for intra-ethnic marriages is completely different due to the large group size (cf. Lanzieri 2012: 1).

Event-history analyses are based on Weibull models. Overall, the Weibull model fits well with regard to our analyses and there is no noteworthy change in results when compared with Cox models (Windzio 2011). However, in contrast to the Cox model, the parametric approach allows a simulation of the effects by using predicted survivor functions (cf. Fig. 3). We apply single and competing risk models. Single risks are defined by the event of moving out. In contrast, competing risks are defined as moving out with marriage and moving out without being married. Moving out with marriage means that both life-events occur more or less simultaneously (within $+/-6$ months). Moving out without being married does not necessarily imply that respondents are not married precisely when they move out, but that they move out of the parental home (at least) 6 months before or after marriage. In the vast majority of cases, respondents do not stay in their parents' home for more than six months after marriage. Hence, competing risks are defined by leaving home either within ("with marriage") or outside ("without marriage") the marriage period of one year.

\section{$4 \quad$ Results}

Figure 1 illustrates the distribution of factor scores of religious norm orientation for German natives and Turkish immigrants (Windzio 2011). These factors were extracted from the items shown in Table A1 (appendix) by using principal component analysis. Signs were reversed so that high factor scores measure high levels of religious norm orientation. It should be noted that this measurement is only cross-sectional, taken at the time of the interview. This is, in most cases, some years after the persons moved out of the parental home, so the causal interpretation is always based on the assumption of rather stable orientations. Most studies on the religiousness and spirituality over the life-course analysed Christian respondents and indicate a slight increase of religiousness over the life-course, especially for persons who already were religious earlier in life, while the overall change does not seem to be 
Fig. 1: Religiosity, factor scores

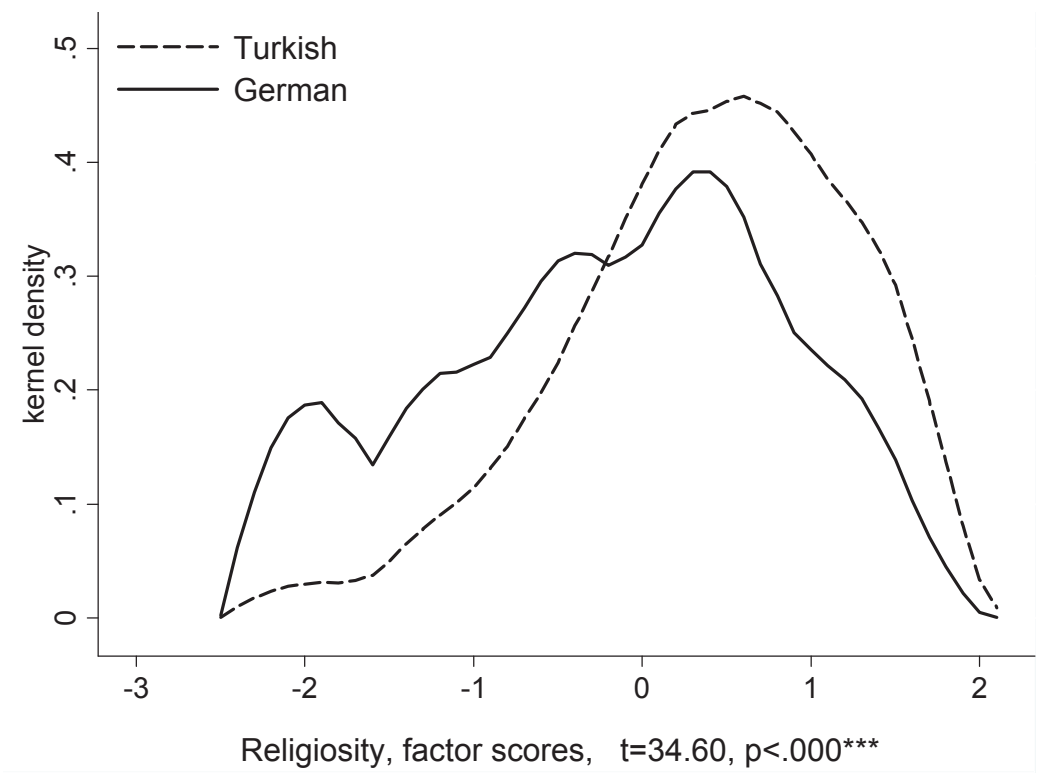

$\mathrm{N}=12555$, Turkish $=3976$, German $=8579$

Source: German GGS, wave 1, 2006, own calculations, see Windzio (2011: 193)

pronounced (Argue et al. 1999; McCullough et al. 2005; Wink/Dillon 2002). Even though some measurement error can obviously be expected, the consequence of such an error is an underestimation of the effects, and therefore not detrimental to the study (Skrondal/Rabe-Hesketh 2004: 76).

Overall, the Turkish population tends towards higher levels of religious norm orientation. Following our argument above, this distinct difference motivates us to focus on this norm orientation as a determinant of the process of leaving the parental home. Before we test the hypotheses in a multivariate event-history design, the following graphs give a first visual impression of the process. In figure 2, the time-axis has been rescaled, so that the period at risk starts at the age of 14. Events of moving out of the parental home taking place before the $14^{\text {th }}$ birthday are seldom and were excluded from the data.

Figure 2 compares the process of moving out of the parental home between German natives and Turkish immigrants. Regarding the median age of moving out, Turkish immigrants move out later (22.1 years) than native Germans ( 20.5 years). There are also gender differences. In both groups, women move out earlier than men, which may very well result from their younger age of marriage on average. The result of the Wilcoxon-Test is highly significant $\left(\chi^{2}(\mathrm{df})=333.77(3)\right)$, and this also holds true if we test for ethnic differences separately by gender (women $\left(\chi^{2}(d f)=36.12(2)\right.$, $p<.000)$, men $\left.\left(\chi^{2}(d f)=141.30(2), p<.000\right)\right)$. The question of whether marriage actually is an important determinant of moving out will be analysed by using models of event history analysis in the following section. 
Fig. 2: Leaving home, by ethnic group and gender

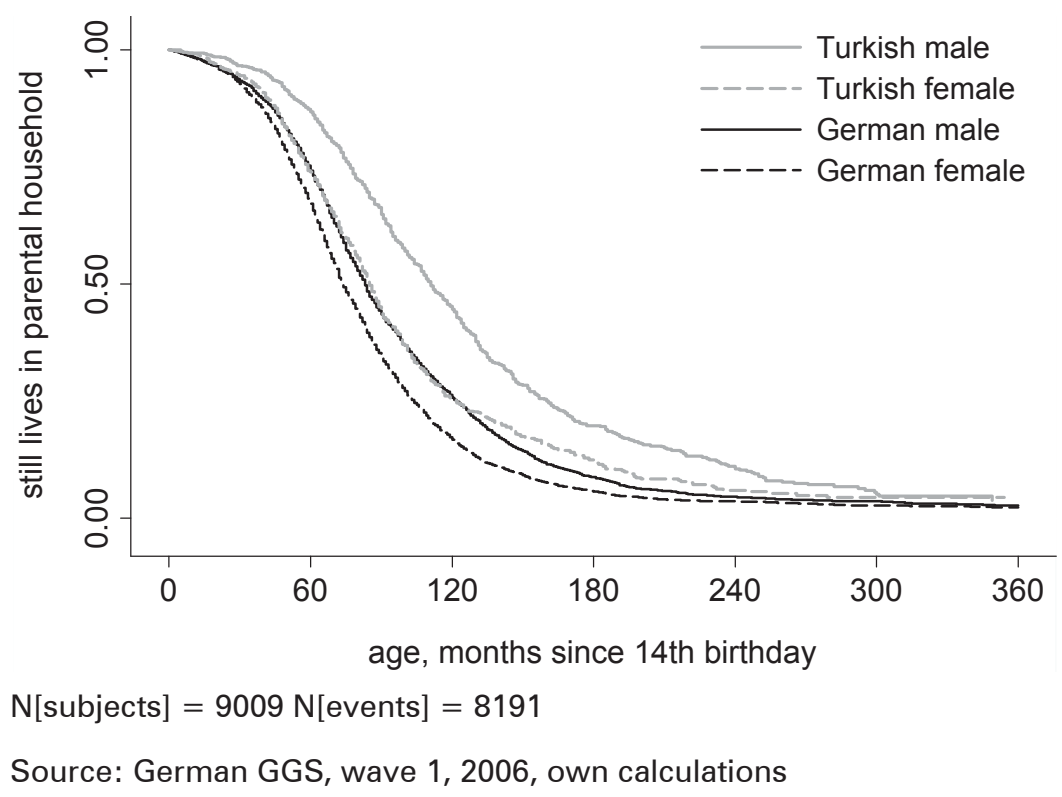

\subsection{Leaving the Parental Home as a Life-Course Transition}

Although the obvious strength of presenting Kaplan-Meier survivor functions lies in the clear illustration of the process for different subgroups, the shortcoming is their limitation in controlling for intervening life-events (Billari 2001; Kley/Huinink 2006). As a result, multivariate event-history models were estimated in order to analyse the effects of different life-course transitions (moving out, marriage and childbirth) and religious norm orientation on leaving the parental home.

In the first two columns of Table 1, the effects of Weibull event-history models are shown for Turkish immigrants and native Germans. Columns 3-6 show the results of models estimated separately for Turkish and German men and women. At first sight, cohort effects suggest a clear pattern of acceleration across cohorts in the native German sample, but no systematic pattern in the Turkish sample. However, estimating the models separately for gender reveals that German women are the only group in which we find such a clear pattern: the younger the cohort of native German women, the higher the rate and the earlier they leave their parents' home. In the first two models we find a positive effect of female gender on the rate at which persons move out of the parental home, which is in line with the survivor functions in Figure 2. In all models, the number of siblings was controlled for as a rough indicator of household "crowding", that is, many people sharing only a limited number of rooms. This indicator is limited insofar as we only know the number of siblings in the data, but not how many of these siblings were still living in the parental household when the respondent moved out. Nevertheless, our indicator of crowding increases the rate of moving out only in the native German sample, but 
not in the Turkish sample, although the average number of siblings (including the respondent) amounts to 1.8 for Germans and 3.3 for Turkish immigrants. If crowding indicates an objective need to move out due to a scarcity of living space (room at home), we would expect significant, positive effects in both samples and not only for native Germans.

The results of these models are also interesting with regard to respondents' educational levels. Compared with the low-educated reference group, highly educated native Germans move out earlier, even though the effect is significant only at the 10 percent level for German women. In the Turkish group, respondents' educational levels do not have any impact, neither for women nor for men.

Regarding social background, measured as parental occupational status when the respondent was 15 years old, we find that children of blue-collar workers move out later than the children of white-collar workers, professionals or civil-servants, which holds true for all subgroups. Moreover, female children of unemployed Turkish parents (or of Turkish parents who are inactive on the labour market) have a lower rate of moving out than the reference group. With respect to the age of immigration (in the Turkish sample) the pattern is less clear. Respondents who immigrated at the age of 18 or above have the lowest rates of leaving the parental home (hazard ratio $0.539, \mathrm{p}<=0.000$ ). Maybe, this indicates that children who immigrated with their parents in late adolescence, are a selective subgroup who tend to stay in their parents' household for unobserved reasons.

Regarding the models in the first two columns in Table 1, there is a negative main effect of religious norm orientation on the rate of moving out, but a positive interaction with the marriage period in both samples. Regardless of their ethnic origin, persons with high levels of religious norm orientation move out later. However, during the marriage period this negative effect is at least compensated for, as the reversed sign of the interaction indicates (Turkish: religiosity $=0.885, p<=0.01$, religiosity ${ }^{*}$ marriage $=1.215, \mathrm{p}<=0.01$ ). This basic pattern remains stable across all subgroups, except for Turkish women, for whom we do not find significant effects. Thus we can conclude from this analysis that religiousness does affect the process of leaving the parental home.

As an intervening life event, the training/higher education period significantly increases rates of moving out in the German sample, even if we estimate the models separately for men and women. In contrast, there is no such effect of training for Turks, be it for men or for women.

Relative to the marriage period, the rate of moving out before marriage - denoted as pre-marital residential autonomy by Goldscheider and Goldscheider (1993) - is decreased by factor 0.107 in the German and by 0.059 in the Turkish sample. In other words, there seems to be a much stronger effect of the marriage period (vs. pre-marital residential autonomy) in the Turkish than in the German group (factor $1 / 0.059=16.950$ vs. factor $1 / 0.107=9.346$ ). This means that firstly, the coincidence of life events - in this case, marriage and leaving the parental home - is important for Germans as well as for Turkish immigrants, but the linkage of both events seems to be much tighter in the group of Turkish immigrants. Further, gender differences with respect to the strength of this effect are only marginal in the German sample, but 
114 - Michael Windzio, Can Aybek

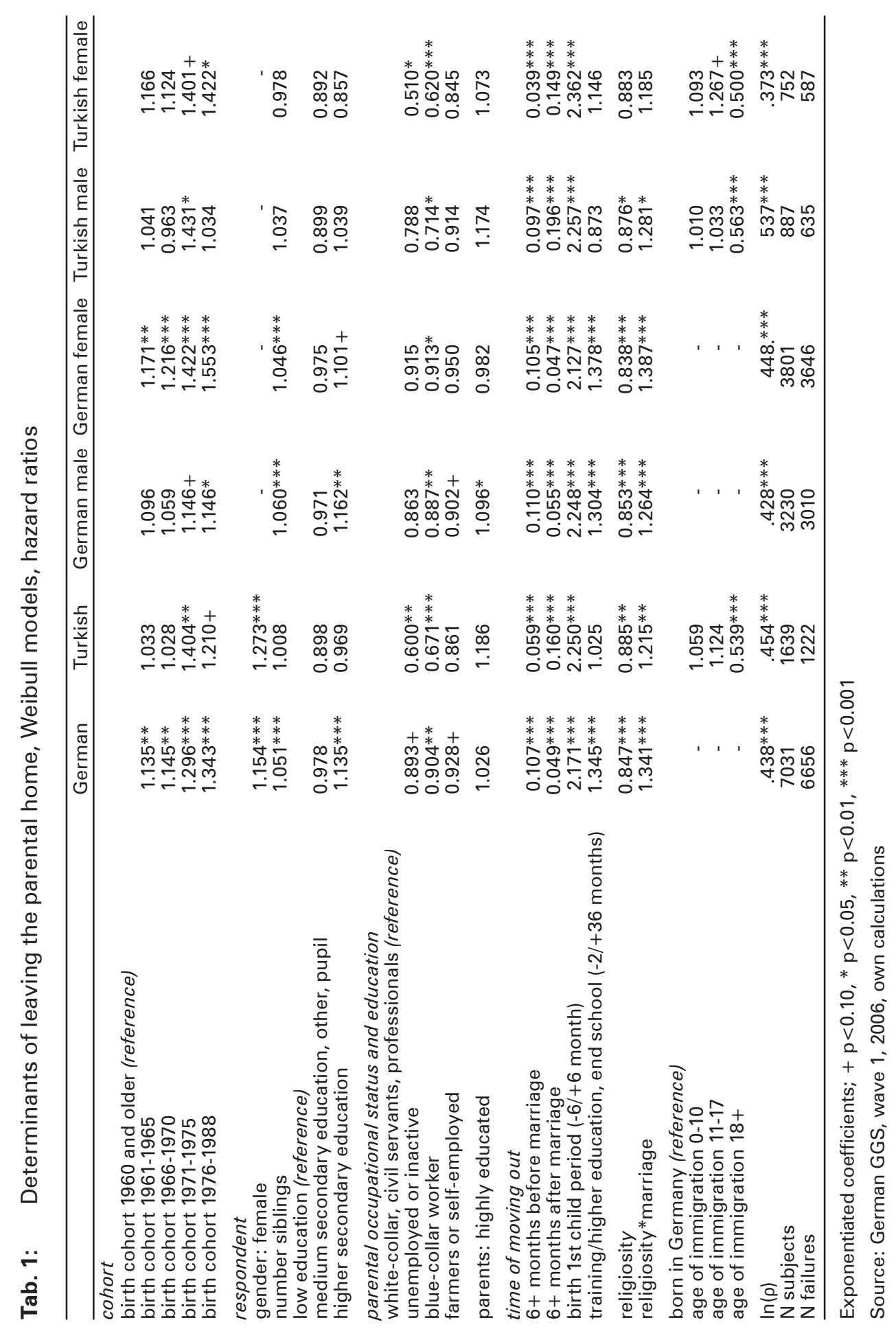


Fig. 3: Effects of marriage on leaving the parental home for women, simulation from Table A1, appendix, all controls held constant at mean values

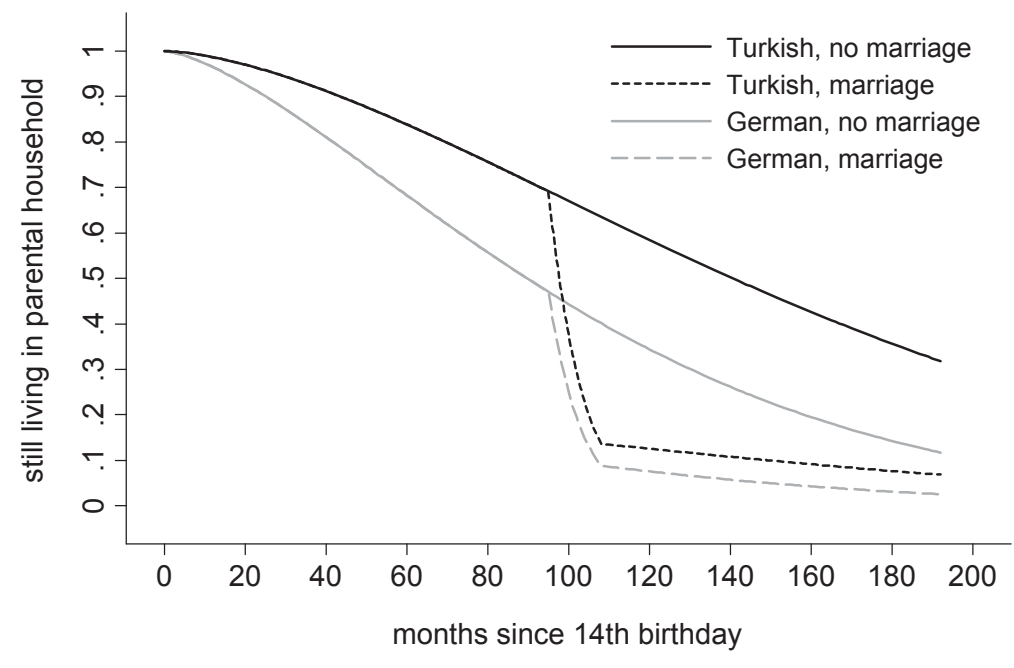

$\mathrm{N}[$ subjects $]=4553 \mathrm{~N}[$ events $]=1339$

Source: German GGS, wave 1, 2006, own calculations

remarkably strong in the Turkish sample. When entering the marriage period, the rate of moving out of the parental home increases by factor 26 for Turkish women (1/0.039), but only by factor 10 for Turkish men (1/0.097). Accordingly, the linking of life-events is much more important for Turkish women than for Turkish men, whereas German men and women do not notably differ from each other.

In order to clarify the difference in the marriage periods' effect size between German women and Turkish women, we use a simulation approach, graphed in figure 3. This approach avoids the problem of comparing coefficients across non-linear models (Mood 2010). Figure 3 is a conditional effect plot of survivor functions. The simulation is based on the two models in Table A3 in the appendix. In the simulated scenario, marriage takes place at the age of 22 years and 6 months (which is 102 months after the 14th birthday). Hence the marriage period, set to 12 months (+/- 6 months around the marriage date), begins in month 96 and ends in month 108. In this model, all control variables are held constant at their mean values. The result is a remarkable difference between Turkish and German women: after 108 months (6 months after marriage), the proportion of German women still living in the parental household is only 8.8 percent. If these German women had not married, 40.1 percentwould still live in the parental household (difference: 31.3 percentage points). In contrast, 13.6 percent of Turkish women who married at the age of 22 and 6 month remain in the parental household. If they had not married, this proportion would amount 63.5 percent, which makes a difference 49.9 percentage points. Therefore, the marriage period causes 18.3 percentage points more events of leaving the parental home for Turkish than for German women. 


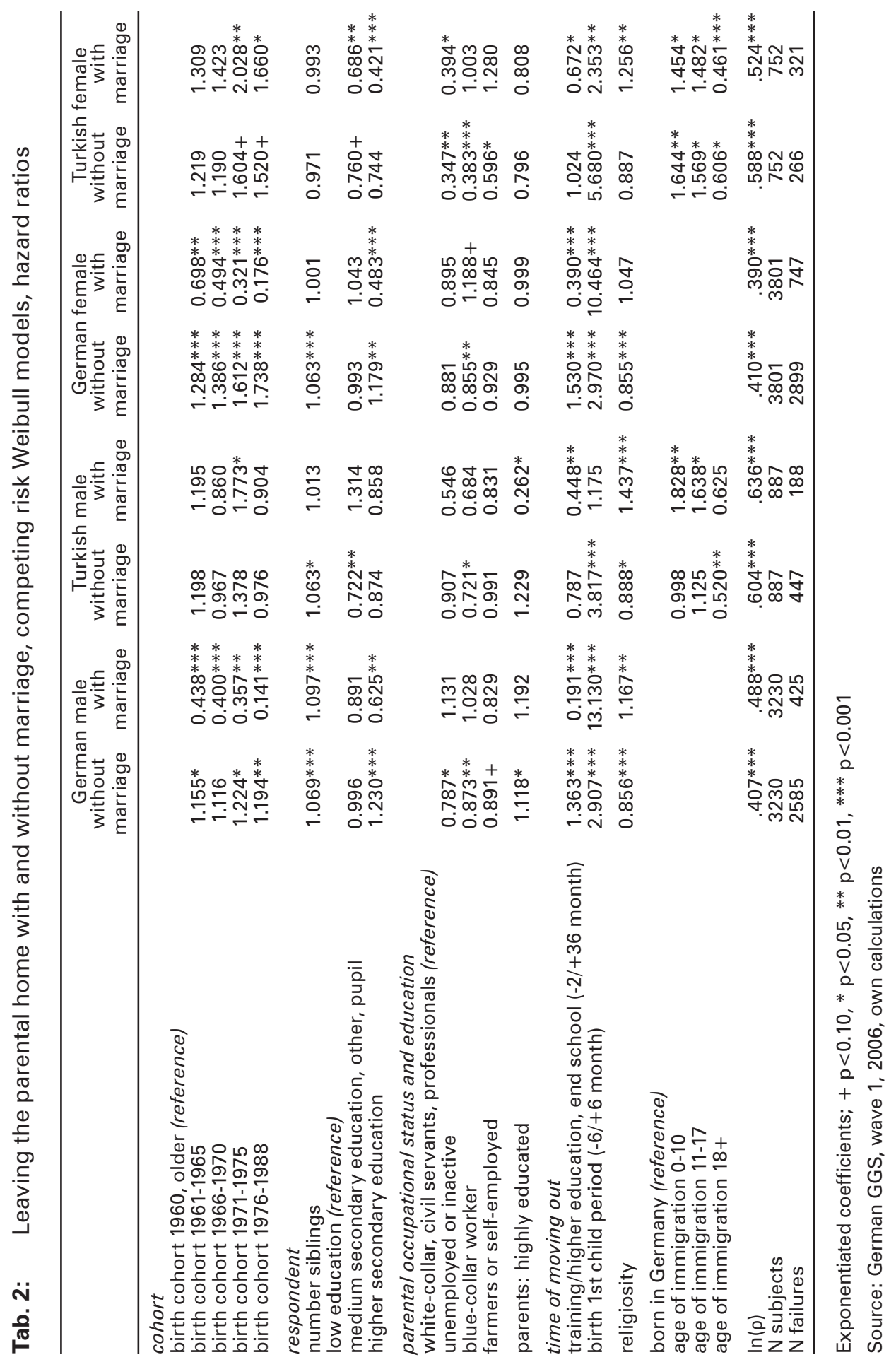


In Table 2, we follow the approach of Zorlu and Mulder (2011) and estimate competing-risk models. The event of leaving home is split into moving out without marriage and moving out with marriage. Again, "at the same time" does not mean perfect synchronicity of marriage and moving out, but a time interval of $+/-6$ months around the date of marriage.

Table 2 shows estimates for Turkish immigrants and native Germans separately for men and women. Here, we can see remarkable differences in cohort effects: for German men and German women, the rate of moving out without marriage increases across cohorts, while the rate of moving out with marriage decreases. Thereby, the trend seems to be more steady-linear for German women than for German men. However, in the Turkish group we do not find such a trend: even though the rate of moving out without marriage increases across cohorts for Turkish women (significant at the 10 percent level), though not steadily, there even seems to be an increase in the rate of moving out with marriage in the 1971-75 and 1976-1988 cohorts. These cohort effects are also significant for the events of moving out with marriage, but only at the 10 percent level. Accordingly, there was a successive decline of the coincidence of moving out and marriage in the German group, but not in the Turkish group. One could argue that the reference group of Turkish respondents who were born before 1960 and who left their families' home in Germany might be exceptional: either, their families were "early movers" since the recruitment agreement between Turkey and Germany was signed in 1961, or they were comparatively old when their families emigrated to Germany in the 1970s or later. However, we do not find a declining trend in the subsequent cohorts, so the effect is not a result of choosing a rather exceptional reference group

In the native German group, for men and women, high education ("higher secondary education" compared with the reference group of low education) corresponds with higher rates of leaving home without marriage and, at the same time, leads to lower rates of leaving home with marriage. This is consistent with our expectations, since highly educated respondents often postpone marriage and move out in order to complete tertiary education or other forms of higher or further education. While higher education decreases the rates of moving out with marriage for Turkish women, it also reduces the rates of moving out without marriage for both Turkish men and women (albeit insignificantly). This means that, contrarily to native Germans, leaving home cannot be primarily considered an instrument towards pursuing higher education in the Turkish group.

Regarding employment and the occupational status of parents, it is rather striking that children of blue-collar workers or unemployed persons (when the respondent was 15 years of age) show lower rates of leaving the parental home without marriage for all four groups. Yet, even though not directly comparable, the differences in effect sizes are especially high for Turkish women: compared with blue-collar workers, the reference group of children whose parents were either white-collar workers, civil servants or professionals have 2.61 times higher rates of moving out without marriage (1/.383). For German women, this rate is increased only by factor $1.17(1 / .855)$. 
A high educational level of parents also has an impact. For Turkish men, it reduces the risk of leaving home with marriage by factor 0.26 . Given the low average educational level of Turkish immigrants in Germany (Diefenbach 2007), highly educated Turkish parents might be a special group which is somewhat different from other Turkish immigrants in terms of value and norm orientations, and that possibly does not strictly follow the norm of coinciding life-events. At the very least, it is striking that a highly qualified parental background makes a difference with respect to the coincidence of life events in the Turkish sample, but not in the native German one - indicating that the behavioural difference between the highly educated and others is more pronounced in the Turkish group.

As expected, the vocational training and higher education period has a positive effect on the rate of leaving home without marriage for native Germans and a negative effect on the rate of leaving home with marriage. While the negative effects on moving out with marriage are nearly identical for German men and German women, the effect on moving out without marriage is not significant in the Turkish group. Hence, moving out in order to pursue educational ambitions is more prevalent in the German sample, and it seems that Turkish immigrants - both men and women - arrange their training or higher education while remaining under direct parental supervision during this period. It seems that the family and marriage norms are so dominant in the Turkish sample that education plays only a minor role for leaving home. Therefore, the education effect might be closely linked to the marriage norm effect. The birth of the first child strongly increases both competing risks, but the effect on moving out in conjunction with marriage is much higher, which is consistent with common expectations: quite often, the events of marriage and the birth of the first child are closely linked to each other. Yet we find especially strong effects of childbirth in the native German sample, where it occurs in an even more pronounced way (e.g. German male: factor 2.90 without vs. factor 13.13 with marriage). However, the effect differs in the Turkish sample: for Turkish men, the birth of the first child does not influence the rates of moving out with marriage, but it increases the rates of moving out without marriage by factor 3.82. For Turkish women, we find significantly positive effects of the birth of the first child for both events, but the effect on moving out without marriage is even stronger than on moving out with marriage. Once again, there is a remarkable difference between the Turkish and the German group: for both German women and men, there is a high coincidence of three events: childbirth, marriage and leaving the parental home. For Turkish men and women, in contrast, the rate of moving out without marriage is increased especially strongly due to childbirth. Since we also know from our analysis in Table 1 that moving out before marriage is a comparatively rare event, particularly for Turkish women, the strong effect of childbirth on moving out without marriage indicates that moving out often takes place after the marriage period: the married women has given birth to a child, but still lives with the parents. Unfortunately, the data does not provide further information on whether the young couple lives together in the husband's parents household - which is a frequent pattern in the group of Turkish immigrants (Gonzalez-Ferrer 2006). Nevertheless, for Turkish immigrants, the first child has a much stronger positive effect outside the marriage period than inside 
it. Once more, this is a striking difference between native Germans and Turkish immigrants. We have to recall the coding of both variables in order to understand this result: the period "birth of the first child" is measured as a one-year interval, with the date of birth as a midpoint. The same logic was applied for defining the marriage period and the competing risks. Giving birth to the first child during the marriage period and moving out during these twelve months is only likely if conception occurred while the respondent was unmarried and living with his or her parents. What we observe in the Turkish sample is a high probability of childbirth after the one-year marriage period has elapsed. Hence the insignificant effect of childbirth on leaving the parental home in conjunction with marriage for Turkish men might result from the fact that for respondents still living in their parents' household, premarital pregnancies rarely occur. For this reason, the birth of the first child does not occur before or during the marriage period, but in most cases afterwards, which is another difference between native Germans and Turkish immigrants.

\subsection{Leaving the Parental Home in a Sequence of Transitions}

A closer look at the frequency distribution of life-course sequences in Table 3 corroborates the result that pre-marital pregnancies rarely occur in the Turkish sample. We used the "sequence concept" of Sackmann and Wingens (2003), which includes an origin state, a destination state and an intermediate state.

When we distinguish between male and female respondents, considerable differences between sequences of Turkish and native German respondents become apparent. 27.90 percent of Turkish men, but only 13.90 percent of German men, follow a "traditional" sequence of marrying first, then moving out and finally making the transition into parenthood. For females, these differences are even stronger: more than 50.07 percent of Turkish women and only 17.41 percent of German women follow this pattern. Similarly, 32.58 percent of Turkish men, but only 11.35 percent of German men, show a sequence that indicates close bonds to the family of origin even after marriage: first they marry, then have a first child and move out afterwards. Shares of this pattern are 19.19 percent for Turkish women and 9.48 percent for German women, respectively. Regarding these two paths beginning with marriage, we see that nearly 70 percent of Turkish women do not have the experience of pre-marital residential autonomy. In contrast, more than 65 percent in the group of German women make this experience. Paths beginning with childbirth rarely occur in both groups and the differences are only slightly significant, if at all. Finally, the two paths of pre-marital residential autonomy (Goldscheider/Goldscheider 1993) are far more prevalent in the German sample: these are sequences starting with leaving the parental home, having a first child and marriage (men: 6.44 percent vs. 16.8 percent, women: 8.21 percent vs. 21.85 percent) as well sequences starting with leaving the parental home, marriage and having a first child (men: 25.38 percent vs. $\mathbf{5 2 . 3 8}$ percent, women: $\mathbf{1 5 . 3}$ percent vs. $\mathbf{4 2 . 2}$ percent).

Can these differences be explained by religious norm orientation as an indicator of cultural difference? Interestingly, in Table 4, religious norm orientation makes a strong difference for native German, but not for Turkish immigrant women! Re- 
Tab. 3: Sequence patterns of life events, by ethnic group, in \%

\begin{tabular}{lrrrr}
\hline & \multicolumn{2}{c}{ male } & \multicolumn{2}{c}{ female } \\
sequence pattern & Turkish & German & Turkish & German \\
\hline marriage $\rightarrow$ move $\rightarrow$ child & 27.90 & $13.90^{* * *}$ & 50.07 & $17.41^{* * *}$ \\
marriage $\rightarrow$ child $\rightarrow$ move & 32.58 & $11.35^{* * *}$ & 19.19 & $9.48^{* * *}$ \\
child $\rightarrow$ marriage $\rightarrow$ move & 5.68 & $3.39^{*}$ & 4.87 & 5.33 n.s. \\
child $\rightarrow$ move $\rightarrow$ marriage & 2.02 & $2.17 \mathrm{n} . \mathrm{s}$. & 2.36 & $3.73^{*}$ \\
move $\rightarrow$ child $\rightarrow$ marriage & 6.44 & $16.80^{* * *}$ & 8.21 & $21.85^{* * *}$ \\
move $\rightarrow$ marriage $\rightarrow$ child & 25.38 & $52.38^{* * *}$ & 15.30 & $42.20^{* * *}$ \\
$\mathrm{~N}=7726$ & 100.00 & 100.00 & 100.00 & 100.00 \\
& 792 & 2625 & 719 & 3543 \\
\hline
\end{tabular}

Source: German GGS, wave 1, 2006, own calculations, significance test based on marginal effects of multinomial logistic regressions

garding the pattern "marriage $\rightarrow$ move $\rightarrow$ child", we find, for instance, significantly higher shares of highly religious German women. In contrast, in the category "move $\rightarrow$ child $\rightarrow$ marriage", highly religious women show significantly lower shares than less religious women. A main conclusion from this Table is that the difference in leaving-home patterns between German and Turkish women is not due to differences in religious norm orientation. Therefore, researchers should search for other explanations. Literature from cross-cultural psychology highlights the protectiveness displayed towards daughters, as an element of "culture of honour", that is supposed to result from differences in the modes of economic production in specific geographic and institutional contexts (e.g. herding economies in mountainous

Tab. 4: Sequence patterns of life events, by ethnic group and religious norm orientation, in \%, women only

\begin{tabular}{lrrrrr}
\hline & $\begin{array}{c}\text { religious norm } \\
\text { orientations }\end{array}$ & \multicolumn{2}{c}{ Turkish } & \multicolumn{2}{c}{ German } \\
sequence pattern & low & high & low & high \\
\hline marriage $\rightarrow$ move $\rightarrow$ child & 50.00 & $51.64 n . s$. & 14.37 & $20.32^{* * *}$ \\
marriage $\rightarrow$ child $\rightarrow$ move & 18.39 & 19.40 n.s. & 8.61 & 10.02 n.s. \\
child $\rightarrow$ marriage $\rightarrow$ move & 4.02 & $5.67 n . s$. & 5.70 & 4.93 n.s. \\
child $\rightarrow$ move $\rightarrow$ marriage & 2.30 & 2.69 n.s. & 4.33 & 3.18 n.s. \\
move $\rightarrow$ child $\rightarrow$ marriage & 9.20 & $6.57 n . s$. & 25.83 & $18.24^{* * *}$ \\
move $\rightarrow$ marriage $\rightarrow$ child & 16.09 & 14.03 n.s. & 41.15 & 43.32 n.s. \\
$\quad \mathrm{N}=4193$ & 348 & 335 & 1684 & 1826 \\
\hline
\end{tabular}

Source: German GGS, wave 1, 2006, own calculations, significance test based on marginal effects of multinomial logistic regressions, median split for religious norm orientation 
regions with weak formal institutions) (Nisbett/Cohen 1996). In combination with a possible persistence of such norm orientation after migration, this could be an alternative explanation (Nisbett/Cohen 1996). However, this line of argument has not yet been systematically adapted towards the integration of immigrants and has only in rare cases been applied in empirical research (Enzmann et al. 2004).

\section{$5 \quad$ Summary and Conclusion}

The impact of marriage on leaving the parental home is particularly strong and gender-specific in the Turkish sample, while we find only negligible gender differences for native Germans. One of the most striking results of this paper is that during the marriage period, the risk of leaving home is increased by factor 20 in the group of Turkish women, while German women have risk ratios of roughly factor 10.

One could argue, however, that strong effects of the marriage period on the rates of moving out mainly reveal economic differences between German natives and Turkish immigrants. But as effects were still in operation even after we controlled for parental occupational status and education, an answer had to be sought for why this pattern is gender-specific. Here, we argued that differences in religiosity could explain the rates of leaving home. We found significant interaction effects, indicating that the decelerating effect of high religiousness was counterbalanced during the marriage period for Turkish and German men as well as German women, but not for Turkish women. However, further results are not in line with the expectation that religiousness could explain differences between native Germans and Turkish immigrants: differences in religious norm orientation do not explain differences in the sequence patterns of leaving the parental home.

In addition, the effect of vocational training or higher education periods also differs between Turkish immigrants and native Germans. It considerably increases the rates of moving out for German men and women, but does not have any effect for the Turkish group. Accordingly, for native Germans, education is a good reason to leave home, but not so for Turkish immigrants. Turks seem to arrange their educational biographies in a way that allows them to stay in the parental home and possibly subordinate their educational aspirations to the needs or expectations of their family. A similar pattern is suggested with respect to the effects of crowding. Although crowding indicates an objective need to reduce room scarcity at home by moving out, it has no effect for the Turkish group, but it significantly increases the moving out of native Germans - even though the average number of siblings is much higher for Turks.

Finally, competing risk models on rates of leaving the parental home with and without marriage revealed important cohort effects: while rates of moving out in conjunction with marriage steadily decreased across German birth-cohorts, indicating a continuous process of the "de-linking" of life-events and individualisation, we did not find analogous processes in the sample of Turkish immigrants. In contrast, the Turkish birth-cohort 1971-75 even showed higher rates of leaving home with marriage than the reference group and all other cohorts (which did not significantly 
differ from the reference group). The "de-linking" of life-events indicates a change in normative orientation towards the transition to adulthood. Such changes in transition-related norms cannot only be measured by appropriate items in surveys, but also by the degree of actual coincidence between crucial life events of marriage and moving-out behaviour. As we have seen in the empirical analysis, despite the control of religious norm orientation, a very strong and consistent effect of this coincidence is observable. Obviously the degree of coincidence of these two life events cannot be explained by religious norm orientation. There actually is an effect of religious norm orientation on leaving home, but this effect is only observable in the native German sample.

The empirical analyses in this paper suffer from at least two shortcomings: first, the measure of religious norm orientation is only cross-sectional. This presupposes the assumption of rather stable value orientation over the life-course - which cannot be tested using this data set. Second, some measurements are only proxy indicators. For instance, the number of siblings as an indicator of crowding is not a perfect one, since it does not take into account the number of rooms or the housing space right before moving out. Similarly, our measurements of the economic situation, the vocational training/higher education period and the composition of households at the time of moving out are far from being perfect. However, we cannot rule out that - at least partially - the differences between Turkish immigrants and Germans natives with regard to the association of marriage and moving out result from economic differences (which correspond with dwelling size, e.g.). We control for the number of siblings, but admittedly this does not fully capture the economically determined effect of household crowding as the amount of siblings could not be put in relation to the total space available in the dwelling (cf. Murphy/Wang 1998).

It is necessary to further investigate and discuss whether the process of leaving the parental home represents a good indicator of acculturation and assimilation processes or not, but for now we might conclude that there are remarkable differences between both groups in this respect, especially with regard to gender-specific patterns. In the Turkish immigrants' sample, individualisation and "de-structuring", or "de-linking" of life-events, did not take place in the same way as it did for native Germans. Hence our empirical results provided evidence that family-related processes clearly differ between both groups.

\section{References}

Argue, Amy; Johnson, David R.; White, Lynn K. 1999: Age and Religiosity: Evidence from a Three-Wave Panel Analysis. In: Journal for the Scientific Study of Religion 38,3: 423-435 [URN: http://www.jstor.org/stable/1387762].

Billari, Francesco C. 2001: The Analysis of Early Life Courses: Complex Descriptions of the Transition to Adulthood. In: Journal of Population Research 18,2: 119-142 [doi: 10.1007/BF03031885].

Billari, Francesco C.; Liefbroer, Aart C. 2007: Should I Stay or Should I Go? The Impact of Age Norms on Leaving Home. In: Demography 44,1: 181-198 [doi: 10.1353/ dem.2007.0000]. 
Blossfeld, Hans-Peter; Golsch, Katrin; Rohwer, Götz 2007: Event History Analysis with Stata. Mahwah/New Jersey: Lawrence Erlbaum Associates.

Corijn, Martine; Klijzing, Erik (Eds.) 2001: Transitions to Adulthood in Europe. Dordrecht: Kluwer Academic Publishers.

Diefenbach, Heike 2007: Kinder und Jugendliche aus Migrantenfamilien im deutschen Bildungssystem. Wiesbaden: VS Verlag.

Diehl, Claudia; Koenig, Matthias 2009: Religiosität türkischer Migranten im Generationenverlauf: Ein Befund und einige Erklärungsversuche. In: Zeitschrift für Soziologie 38,4: 300-319 [URN: http://www.jstor.org/stable/23773350].

Diehl, Claudia; Koenig, Matthias; Ruckdeschel, Kerstin 2009: Religiosity and Gender Equality: Comparing Natives and Muslim Migrants in Germany. In: Ethnic and Racial Studies 32,2: 278-301 [doi: 10.1080/01419870802298454].

Enzmann, Dirk; Brettfeld, Katrin; Wetzels, Peter 2004: Männlichkeitsnormen und die Kultur der Ehre. Empirische Prüfung eines theoretischen Modells zur Erklärung erhöhter Delinquenzraten jugendlicher Migranten. In: Oberwittler, Dietrich; Karstedt, Susanne (Eds.): Soziologie der Kriminalität. Wiesbaden: VS Verlag: 266-287.

Esmer, Yilmaz 2008: Islam, Gender, Democracy and Values: The Case of Turkey, 19902001. In: Pettersson, Thorleif; Esmer, Yilmaz (Eds.): Changing Values, Persisting Cultures. Case Studies in Value Change. European values studies 12. Leiden: Brill: 275 301.

Ette, Andreas; Hullen, Gert; Leven, Ingo; Ruckdeschel, Kerstin 2007: Generations and Gender Survey. Dokumentation der Befragung von türkischen Migranten in Deutschland. Materialien zur Bevölkerungswissenschaft. Wiesbaden: Bundesinstitut für Bevölkerungsforschung.

Gerhards, Jürgen 2004: Europäische Werte - Passt die Türkei kulturell zur EU? In: Aus Politik und Zeitgeschichte B 38: 14-20.

Goldscheider, Frances K.; Goldscheider, Calvin 1993: Leaving Home before Marriage. Ethnicity, Familism, and Generational Relationships. Madison, WI: University of Wisconsin Press.

Gonzalez-Ferrer, Amparo 2006: Who Do Immigrants Marry? Partner Choice Among Single Immigrants in Germany. In: European Sociological Review 22,2: 171-185 [doi: 10.1093/esr/jci050].

Halpern, David 2006: Social Capital. Oxford: Polity Press.

Hortaçsu, Nuran 2003: Marriage in Turkey. In: Ingoldsby, Bron B.; Hamon, Raeann R. (Eds.): Mate Selection Across Cultures. Thousand Oaks, CA: SAGE: 155-171.

Hortaçsu, Nuran 2007: Family- Versus Couple-Initiated Marriages in Turkey: Similarities and Differences Over the Family Life Cycle. In: Asian Journal of Social Psychology 10,2: 103-116 [doi: 10.1111/j.1467-839X.2007.00217.x].

Huschek, Doreen; Valk, Helga A. G. de; Liefbroer, Aart C. 2010: Timing of First Union among Second-Generation Turks in Europe: The Role of Parents, Peers and Institutional Context. In: Demographic Research 22,16: 473-504 [doi: 10.4054/DemRes.2010.22.16].

Kağıtçıbaşı, Çiğdem; Sunar, Diane 1997: Familie und Sozialisation in der Türkei. In: Nauck, Bernhard; Schönpflug, Ute (Eds.): Familien in verschiedenen Kulturen. Stuttgart: Enke: 145-161.

Kalaycıoğlu, Sibel; Rittersberger-Tılıç, Helga 2000: Intergenerational Solidarity Networks of Instrumental and Cultural Transfers within Migrant Families in Turkey. In: Ageing \& Society 20,5: 523-542 [doi: 10.1017/S0144686X99007916]. 
Kalter, Frank; Granato, Nadia 2004: Sozialer Wandel und strukturelle Assimilation in der Bundesrepublik. In: IMIS Beiträge 23: 61-81.

Kalter, Frank; Schroedter, Julia H. 2010: Transnational Marriage among Former Labour Migrants in Germany. In: Zeitschrift für Familienforschung - Journal of Familiy Research 22,1: 11-36 [doi: 10.5167/uzh-39870].

Kley, Stefanie; Huinink, Johannes 2006: Die Gründung des eigenen Haushalts bei Ostund Westdeutschen nach der Wiedervereinigung. In: Zeitschrift für Bevölkerungswissenschaft 31,1: 127-154.

Koç, Ismet 2007: The Timing of Leaving the Parental Home and Its Linkages to Other Life Course Events in Turkey. In: Marriage \& Family Review 42,1: 29-47 [doi: 10.1300/ J002v42n01_03].

Konietzka, Dirk 2010: Zeiten des Übergangs. Sozialer Wandel des Übergangs in das Erwachsenenalter. Wiesbaden: VS Verlag für Sozialwissenschaften.

Konietzka, Dirk; Huinink, Johannes 2003: Die De-Standardisierung einer Statuspassage? Zum Wandel des Auszugs aus dem Elternhaus und des Übergangs in das Erwachsenenalter in Westdeutschland. In: Soziale Welt 54,3: 285-311 [URN: http:// www.jstor.org/stable/40878417].

Lanzieri, Giampaolo 2012: Merging Populations: A Look at Marriages with Foreign-Born Persons in European Countries (Statistics in Focus, 29/2012). Luxembourg: Eurostat [http://ec.europa.eu/eurostat/documents/3433488/5584928/KS-SF-12-029-EN.PDF].

Liljeström, Rita; Özdalga, Elisabeth (Eds.) 2002: Autonomy and Dependence in the Family. Turkey and Sweden in Critical Perspective. Istanbul: Swedish Research Institute.

McCullough, Michael E. et al. 2005: The Varieties of Religious Development in Adulthood: a Longitudinal Investigation of Religion and Rational Choice. In: Journal of Personality and Social Psychology 89,1: 78-89 [doi: 10.1037/0022-3514.89.1.78].

Modood, Tariq; Triandafyllidou, Anna; Zapata-Barrero, Ricard (Eds.) 2006: Multiculturalism, Muslims and Citizenship. A European Approach. London: Routledge.

Mood, Carina 2010: Logistic Regression: Why We Cannot Do What We Think We Can Do, and What We Can Do About It. In: European Sociological Review 26,1: 67-82 [doi: 10.1093/esr/jcp006].

Murphy, Mike; Wang, Duolao 1998: Family and Sociodemographic Influences on Patterns of Leaving Home in Postwar Britain. In: Demography 35,3: 293-305 [doi: 10.2307/3004037].

Nauck, Bernhard 1989: Intergenerational Relationships in Families from Turkey and Germany: an Extension of the "Value of Children" Approach to Educational Attitudes and Socialization Practices. In: European Sociological Review 5,3: 251-274 [http://www. jstor.org/stable/522339].

Nisbett, Richard E.; Cohen, Dov 1996: Culture of Honor: the Psychology of Violence in the South. Boulder, CO: Westview Press.

Portes, Alejandro 1998: Social Capital: Its Origins and Applications in Modern Sociology. In: Annual Review of Sociology 24: 1-24 [doi: 10.1146/annurev.soc.24.1.1].

Portes, Alejandro; Rumbaut, Rubén G. 2006: Immigrant America: a Portrait. $3^{\text {rd }}$ ed. Berkeley: University of California Press.

Ruckdeschel, Kerstin; Ette, Andreas; Hullen, Gert; Leven, Ingo 2006: Generations and Gender Survey. Dokumentation der ersten Welle der Hauptbefragung in Deutschland. Materialien zur Bevölkerungswissenschaft. Wiesbaden: Bundesinstitut für Bevölkerungsforschung. 
Sackmann, Reinhold; Wingens, Matthias 2003: From Transitions to Trajectories: Sequence Types. In: Heinz, Walter R.; Marshall, Victor W. (Eds.): Social Dynamics of the Life Course: Transitions, Institutions, and Interrelations. Hawthorne, NY: Aldine de Gruyter: 93-112.

Schweitzer, Peter P. (Ed.) 2000: Dividends of Kinship: Meanings and Uses of Social Relatedness. London/New York, NY: Routledge.

Segalen, Martine 1986: Historical Anthropology of the Family. Cambridge: Cambridge University Press.

Settersten, Richard A. 1998: A Time to Leave Home and a Time Never to Return? Age Constraints on the Living Arrangements of Young Adults. In: Social Forces 76,4: 13731400 [doi: 10.2307/3005839].

Skrondal, Anders; Rabe-Hesketh, Sophia 2004: Generalized Latent Variable Modeling. Multilevel, Longitudinal, and Structural Equation Models. Boca Raton: Chapman \& $\mathrm{Hall} / \mathrm{CRC}$.

Steinbach, Anja 2013: Family Structure and Parent-Child Contact: A Comparison of Native and Migrant Families. In: Journal of Marriage and Family 75,5: 1114-1129 [doi: 10.1111/jomf.12060].

Weber, Max 1978: Economy and Society: an Outline of Interpretive Sociology. Berkeley, CA: University of California Press.

Weber, Max 1999: The Sociology of Religion. Boston: Beacon Press.

White, James M.; Klein, David M.; Todd, Martin F. 2015: Family Theories: an Introduction. Los Angeles, CA: Sage.

Windzio, Michae/ 2011: Linked Life-Events. How Culture Matters for Leaving Parental Home in Turkish Immigrant and Native Families in Germany. In: Wingens, Matthias; Windzio, Michael; Valk, Helga de; Aybek, Can M. (Eds.): A Life-Course Perspective on Migration and Integration. Dordrecht: Springer: 187-208.

Windzio, Michael; Wingens, Matthias 2014: Religion, Friendship Networks and Home Visits of Immigrant and Native Children. In: Acta Sociologica 57,1: 59-75 [doi: 10.1177/0001699313481226].

Wink, Paul; Dillon, Michele 2002: Spiritual Development Across the Adult Life Course: Findings from a Longitudinal Study. In: Journal of Adult Development 9,1: 79-94. [doi: 10.1023/A:1013833419122].

Zinnecker, Jürgen 1998: Die Tradierung kultureller Systeme zwischen den Generationen. Die Rolle der Familie bei der Vermittlung von Religion in der Moderne. In: Zeitschrift für Soziologie der Erziehung und Sozialisation 18,4: 343-356.

Zorlu, Aslan; Mulder, Clara 2011: Ethnic Differences in Leaving Home: Timing and Pathways. In: Demography 48,1: 49-72 [doi: 10.1007/s13524-010-0012-1]. 
Prof. Dr. Michael Windzio ( $₫)$. EMPAS - Institute of Empirical and Applied Sociology. Bremen, Germany. E-mail: mwindzio@empas.uni-bremen.de,

URL:http://www.empas.uni-bremen.de/index.php?id=86\&no_cache $=1 \& \mathrm{~L}=1$

Prof. Dr. Can Aybek. Hochschule Bremen. University of Applied Sciences. Bremen, Germany. E-mail: Can.Aybek@hs-bremen.de, URL: http://www.can-aybek.eu/ 


\section{Appendix}

Tab. A1: Items indicating religious norm orientation

- How often, if at all, do you attend religious services, e.g. collective prayers?

- It is important for an infant to be initiated/baptised in an appropriate religious ceremony.

- It is important for couples who marry at public registry offices to have a religious wedding too.

- It is important for a funeral to include a religious ceremony.

Cronbach's Alpha $=0.7892$ 
Tab. A2: Descriptive statistics of event-history models

\begin{tabular}{|c|c|c|c|c|}
\hline & mean & sd & $\min$ & $\max$ \\
\hline subepisodes with event & .304 & .460 & 0 & 1 \\
\hline \multicolumn{5}{|l|}{ cohort (Ref.: 1960 and older) } \\
\hline birth cohort 1961-65 & .120 & .325 & 0 & 1 \\
\hline birth cohort 1966-70 & .110 & .313 & 0 & 1 \\
\hline birth cohort 1971-75 & .094 & .293 & 0 & 1 \\
\hline birth cohort 1976-88 & .192 & .394 & 0 & 1 \\
\hline \multicolumn{5}{|l|}{ respondent } \\
\hline Turkish & .527 & .499 & 0 & 1 \\
\hline female gender & .209 & .407 & 0 & 1 \\
\hline number of siblings & 2.151 & 1.846 & 0 & 17 \\
\hline \multicolumn{5}{|l|}{ low education (reference) } \\
\hline medium education & .365 & .481 & 0 & 1 \\
\hline higher secondary education, (Abitur/Fachabitur) & .202 & .401 & 0 & 1 \\
\hline \multicolumn{5}{|l|}{ parental occupational status and education } \\
\hline \multicolumn{5}{|l|}{ parents: no employment (1) (reference) } \\
\hline parents: blue-collar workers (1) & .035 & .184 & 0 & 1 \\
\hline parents: farmers, self-employed & .424 & .494 & 0 & 1 \\
\hline parents: white-collar workers, civil servants, professionals (1) & .123 & .328 & 0 & 1 \\
\hline parents: high education, master craftsmen, academic (Ref.: other) & .209 & .407 & 0 & 1 \\
\hline \multicolumn{5}{|l|}{ time of moving out } \\
\hline $6+$ months before marriage & .860 & .346 & 0 & 1 \\
\hline $6+$ months after marriage & .038 & .191 & 0 & 1 \\
\hline birth 1st child period (+/- 6 Mon.) & .043 & .202 & 0 & 1 \\
\hline training period, end school $-2 /+36$ Mon & .317 & .465 & 0 & 1 \\
\hline \multicolumn{5}{|l|}{ born in Germany (reference) } \\
\hline age of immigration: $0-10$ years & .050 & .218 & 0 & 1 \\
\hline age of immigration: $11-17$ years & .041 & .200 & 0 & 1 \\
\hline age of immigration: $18+$ years & .026 & .161 & 0 & 1 \\
\hline religiosity & -.057 & 1.010 & -2.056 & 1.757 \\
\hline religiosity * marriage period & .014 & .318 & -2.056 & 1.757 \\
\hline
\end{tabular}

$\mathrm{N}$ Subepisodes $=26026, \mathrm{~N}$ Persons $=8734, \mathrm{~N}$ Events $=7933$

sd = standard deviation

Source: German GGS, wave 1, 2006, own calculations 
Tab. A3: Determinants of leaving the parental home, Weibull models, hazard ratios, models for simulation

\begin{tabular}{|c|c|c|}
\hline & German female & Turkish female \\
\hline \multicolumn{3}{|l|}{ cohort } \\
\hline birth cohort 1969-1965 & $1.180 * *$ & 0.959 \\
\hline birth cohort 1966-1970 & $1.266^{* * *}$ & 1.018 \\
\hline birth cohort 1971-1975 & $1.457 * * *$ & 1.175 \\
\hline birth cohort 1976-1988 & $1.587^{* * *}$ & 1.151 \\
\hline \multicolumn{3}{|l|}{ respondent } \\
\hline number siblings & $1.044^{* * *}$ & 0.980 \\
\hline \multicolumn{3}{|l|}{ low education (reference) } \\
\hline medium secondary education, other, pupil & 0.970 & $0.832+$ \\
\hline higher secondary education & $1.099+$ & 0.779 \\
\hline unemployed or inactive & 0.887 & $0.546^{*}$ \\
\hline blue-collar worker & $0.896 * *$ & $0.623 * * *$ \\
\hline farmers or self-employed & 0.917 & 0.820 \\
\hline white-collar workers, civil servants, professionals & 0.980 & 0.971 \\
\hline \multicolumn{3}{|l|}{ time of moving out } \\
\hline$-/+6$ months around marriage & $10.584^{* * *}$ & $19.214^{* * *}$ \\
\hline birth 1st child period (-6/+6 month) & $2.076 * * *$ & $2.829 * * *$ \\
\hline training/higher education, end school (-2/+36 months) & $1.416^{* * *}$ & 1.118 \\
\hline religiosity & $0.843^{* * *}$ & 0.925 \\
\hline religiosity*marriage & $1.386^{* * *}$ & 1.157 \\
\hline age of immigration $0-10$ & - & 1.110 \\
\hline age of immigration $11-17$ & - & $1.314^{*}$ \\
\hline age of immigration $18+$ & - & $0.564^{* * *}$ \\
\hline $\ln (\rho)$ & $.399 * * *$ & $.480 * * *$ \\
\hline $\mathrm{N}$ subjects & 3801 & 752 \\
\hline $\mathrm{N}$ failures & 3646 & 587 \\
\hline
\end{tabular}

Exponentiated coefficients; $+p<0.10,{ }^{*} p<0.05,{ }^{* *} p<0.01,{ }^{* *} p<0.001$

Source: German GGS, wave 1, 2006, own calculations 


\section{Comparative Population Studies}

WWW.comparativepopulationstudies.de

ISSN: 1869-8980 (Print) - 1869-8999 (Internet)

Published by / Herausgegeben von

Prof. Dr. Norbert F. Schneider

Federal Institute for Population Research

D-65180 Wiesbaden / Germany

\section{Managing Editor /}

Verantwortlicher Redakteur

Frank Swiaczny

\section{Assistant Managing Editor /}

\section{Stellvertretende Redakteurin}

Katrin Schiefer

\section{Copy Editor (German) /}

Lektorat (deutsch)

Dr. Evelyn Grünheid

\section{Layout / Satz}

Beatriz Feiler-Fuchs

E-mail:cpos@bib.bund.de

\section{Scientific Advisory Board /}

Wissenschaftlicher Beirat

Paul Gans (Mannheim)

Johannes Huinink (Bremen)

Michaela Kreyenfeld (Rostock)

Marc Luy (Wien)

Clara H. Mulder (Groningen)

Notburga Ott (Bochum)

Peter Preisendörfer (Mainz)

Zsolt Spéder (Budapest)
Board of Reviewers / Gutachterbeirat Martin Abraham (Erlangen)

Laura Bernardi (Lausanne)

Hansjörg Bucher (Bonn)

Claudia Diehl (Konstanz)

Andreas Diekmann (Zürich)

Gabriele Doblhammer-Reiter (Rostock)

Jürgen Dorbritz (Wiesbaden)

Anette Eva Fasang (Berlin)

E.-Jürgen Flöthmann (Bielefeld)

Alexia Fürnkranz-Prskawetz (Wien)

Beat Fux (Salzburg)

Joshua Goldstein (Berkeley)

Karsten Hank (Köln)

Sonja Haug (Regensburg)

Hill Kulu (Liverpool)

Aart C. Liefbroer (Den Haag)

Kurt Lüscher (Konstanz)

Emma Lundholm (Umeå)

Nadja Milewski (Rostock)

Dimiter Philipov (Wien)

Roland Rau (Rostock)

Tomáš Sobotka (Wien)

Jeroen Spijker (Barcelona)

Olivier Thévenon (Paris)

Helga de Valk (Brussel)

Heike Trappe (Rostock)

Michael Wagner (Köln) 